\title{
Blood serum alpha fetoprotein enhancer binding protein, a tumor suppressor, decreases in chronic HBV hepatitis patients as hepatocellular cancer appears
}

\author{
James N. Riggins ${ }^{\mathrm{a}, \mathrm{b}}$, William Corey ${ }^{\mathrm{b}}$, Alfred N. Fonteh ${ }^{\mathrm{a}}$ and Michael G. Harrington ${ }^{\mathrm{a}, *}$ \\ ${ }^{a}$ Molecular Neurology Program, Huntington Medical Research Institutes, Pasadena, CA, USA \\ ${ }^{\mathrm{b}}$ HMRI Liver Center, Pasadena, CA, USA
}

\begin{abstract}
Chronic hepatitis increases the risk of hepatocellular carcinoma (HCC). To test whether circulating proteins reflect hepatic carcinogenesis, sera from patients and controls were albumin depleted, enriched for glycoproteins, digested with trypsin, and subjected to reverse phase chromatography and tandem mass spectrometry. Alpha-fetoprotein enhancer binding protein (AFPebp), a tumor suppressor, was repeatedly identified in sera from chronic HBV hepatitis patients. We independently identified and quantified AFPebp with a deuterated, phenylisocyanate-labeled synthetic peptide standard. Elevated AFPebp levels in sera from chronic HBV hepatitis patients decreased as cancer developed. These data suggest that rising AFPebp levels in chronic HBV hepatitis may be protective, while falling levels may contribute to HCC development.
\end{abstract}

Keywords: Alpha-fetoprotein, alpha-fetoprotein enhancer binding protein, tumor suppressor, hepatitis B virus, hepatitis C virus, hepatocellular carcinoma, liquid chromatography, tandem mass spectrometry, phenylisocyanate, deuterium

\section{Introduction}

HCC ranks fifth in worldwide cancer incidence with approximately 250,000 to 500,000 new cases each year [1]. The underlying causes for HCC are not known, though it usually follows many years of chronic viral hepatitis $(\mathrm{CVH})$. The rate of development of $\mathrm{HCC}$ in $\mathrm{CVH}$ and cirrhosis is approximately $1 \%$ and $2.5 \%$ per year, respectively [1]. Clinical assessments used to assess the onset of HCC are liver ultrasound, biopsy, and serum measures for liver function and alphafetoprotein (AFP) [2]. Ultrasound only allows for the detection of tumors after onset of HCC. Liver function tests are non-specific for the diagnosis of HCC.

* Corresponding author: Michael G. Harrington, Huntington Medical Research Institutes, 99 North El Molino Avenue, Pasadena, CA 91101, USA. Tel.: +1 626795 4343; Fax: +1 626795 5774; E-mail: mghworks@hmri.org.
AFP, the current standard, has been shown to increase in some HCC cases (30-60\%) [3-11], glycosylation changes alter in HCC [12-14], and it may be useful as a prognostic marker during treatment. A more specific and sensitive test to detect the onset of HCC is needed [3].

Research has focused on finding protein biomarkers for HCC in the sera of at-risk patients using LC-MS, MALDI-MS, SELDI-MS, or 2D gel technologies [9, 10,15-23]. SELDI-TOF has been used to identify complement $\mathrm{C} 3 \mathrm{a}$ as a potential marker for $\mathrm{HCV}+$ induced HCC [19]. MALDI-TOF has been used to identify small peptides that appear related to HCC [24]. Changes in DNA methylation and changes in protein modification have been probed as diagnostic markers $[25,26]$. In a study of sera from patients with hepatitis and hepatitis-induced HCC, hyper-fucosylation of glycoproteins has been related to the development of HCC [13]. HNF4alpha, p53, and Ki-67 have also been 
Table 1

Diagnostic criteria for patient class

\begin{tabular}{lccccc}
\hline & Antibody & HBV-DNA & HCV-RNA & ALT & Histology \\
\hline Normal $(n=16)$ & No AB & - & - & normal & normal \\
HBV Carrier $(n=11)$ & HVsAg & + & - & normal & normal \\
HCV Carrier $(n=6)$ & Anti-HCV & - & + & normal & normal \\
Chronic HBV Hepatitis $(n=42)$ & HBsAg & + & - & elevated & inflammation/cirrhosis \\
Autoimmune Hepatitis $(n=17)$ & ANA & - & - & elevated & inflammation/cirrhosis \\
HBV/HCC $(n=37)$ & HBsAg & + & - & elevated & HCC \& cirrhosis* \\
\hline
\end{tabular}

ALT-alanine aminotransferase.

ANA-anti-nuclear antibodies.

* liver inflammation is observed in only some HCC patients.

suggested as possible markers of HCC [27,28]. It has yet to be determined whether any of these findings will measure $\mathrm{HCC}$ risk or at what stage of the disease they will be relevant for diagnosing cancer [29].

Using shotgun protein sequencing and data analysis, we have identified proteins that change between the time of chronic HBV hepatitis and the onset of HCC. One biomarker candidate identified with this method, alpha-fetoprotein enhancer binding protein (AFPebp), was independently verified using quantitative mass spectrometry. Our data demonstrate that AFPebp levels rise with chronic HBV hepatitis and drop as HCC develops. Thus AFPebp changes reveal pathophysiology between chronic HBV hepatitis and its transition to $\mathrm{HCC}$.

\section{Materials and methods}

\subsection{Study population}

Sera from 129 participants (5-88 years of age) included both archival and prospective samples after giving informed consent based on an ethically approved protocol (human subjects assurance \# FWA 00002338) with diagnostic criteria in Table 1. Sixteen age-, gender- and race-matched controls had no known liver disease, and were negative for hepatitis B surface antigen (HBsAg) and $\mathrm{HCV}$ antibodies. Eleven carrier HBV patients tested positive for HBsAg without elevated alanine aminotransferase (ALT) or aspartate aminotransferase (AST) levels. Six carrier HCV patients had HCV antibodies without elevated ALT/AST levels. Seventeen autoimmune hepatitis patients with antinuclear antibodies and elevated ALT/AST levels had no detectable HBsAg or HCV antibody levels. Forty-two chronic HBV infected patients were positive for HBsAg with elevated ALT/AST levels. Thirty-seven patients had either histological and/or diagnostic imaging confirmation of HCC. Histology was available on all of the subset of ten paired, chronic $\mathrm{HBV}+$ hepatitis patients that progressed to HCC and that were analyzed by quantitative assay for AFPebp: all of these patients had cirrhosis. Patients were excluded if there was evidence of confounding systemic disease, alcoholism, toxic drug exposure, other cancers, abnormal storage disease, HIV, or cytomegalovirus. Sera were obtained by centrifugation of freshly clotted blood and $0.5 \mathrm{~mL}$ aliquots were stored at $-80^{\circ} \mathrm{C}$ until use.

\subsection{Protein assay}

Concentrations of protein in serum were determined using a microplate-based Quant-iT protein assay kit (Invitrogen, Carlsbad, CA) using pre-diluted kit BSA, $0-500 \mu \mathrm{g} / \mathrm{mL}$, as a standard. Briefly, single aliquots of serum or protein standard in triplicates were added to a 96 well microtiter plate. Quant-iT protein reagent was diluted (200X) in Quant-iT protein buffer and $200 \mu \mathrm{L}$ was added to each well. After 45 to $60 \mathrm{~min}$, the fluorescence (excitation/emission at $470 / 570 \mathrm{~nm}$ ) was measured using a microplate reader (Gemini XPS, Molecular Devices, Sunnyvale, CA) and protein concentrations in each sample were determined using Softmax software from Molecular Devices.

\subsection{Serum fractionation}

Our logic is to remove albumin and enrich for glycoproteins so that a search can be made by shotgun sequencing for lower abundance proteins that may reflect the transition from chronic HBV hepatitis to that of HCC. Thus we chose to enrich less abundant proteins and those that are glycosylated, since glycosylation is a major liver activity and has been associated with one of the existing biomarkers, AFP $[8,30,31]$. 


\subsection{Albumin depletion}

Albumin and albumin-like proteins were removed using a HiTrap Blue G column (GE Health Care). Briefly, samples were thawed at room temperature, vortexed and centrifuged to remove any particulate matter. Injections of $0.1 \mathrm{~mL}$ whole sera were made onto an Agilent 1050 LC system equipped with UV detection $(280 \mathrm{~nm})$ for eluting proteins. Serum was passed through GE Health Care HiTrap Blue G ( $5 \mathrm{mg}$ ) columns at a flow rate of $0.3 \mathrm{~mL} / \mathrm{min}$ at ambient temperature in $0.01 \mathrm{mM}$ sodium phosphate buffer at $\mathrm{pH} 7.4$. Flow through fraction was observed between 2-5 min, and collected as Fraction 1 (F1). Elution of column bound proteins was completed by switching to $0.3 \mathrm{~mL} / \mathrm{min}$ $0.01 \mathrm{mM}$ sodium phosphate, $\mathrm{pH} 7.4,0.5 \mathrm{M} \mathrm{NaCl}$ at 7 min post injection. Fraction 2 (F2) eluted between 15-17 min and was collected. The column was washed by returning the eluent conditions to $0.3 \mathrm{~mL} / \mathrm{min}$ of $0.01 \mathrm{mM}$ sodium phosphate buffer at $\mathrm{pH} 7.4$ at $20 \mathrm{~min}$ post injection and maintained for an additional $10 \mathrm{~min}$ before another injection was made.

\subsection{Glycoprotein fractionation}

The flow through fraction $(\mathrm{F} 1)$, which contains mostly non-albumin proteins, was fractionated further based on the glycosylation state of the proteins within the sample. Conconavalin A (ConA) bound Sepharose beads (GE Health Care) were used. F1 was placed onto the Con A Sepharose beads, preconditioned with binding buffer, in a ratio of $0.1 \mathrm{~mL}$ bead suspension to $0.4 \mathrm{~mL}$ of eluted fraction and $0.5 \mathrm{~mL}$ of $2 \mathrm{X}$ binding buffer (20 mM Tris-Cl (pH 7.4), $500 \mathrm{mM} \mathrm{NaCl}, 1 \mathrm{mM}$ $\mathrm{CaCl}_{2}, 1 \mathrm{mM} \mathrm{MgCl} 2,1 \mathrm{mM} \mathrm{MnCl}$ ). Batch purification was completed by mixing the beads with the sample via gentle inversion for $1 \mathrm{hr}$ at ambient temperature. After spinning the Con A Sepharose beads into a pellet, the supernatant, fraction 1A (F1A) (a mixture of glycosylated proteins that did not bind to Con A, and non-glycosylated proteins), was saved. The beads were then washed in $500 \mu \mathrm{L}$ of $1 \mathrm{X}$ binding buffer to remove any non-specifically bound protein by inversion for $30 \mathrm{~min}$ at ambient temperature. The beads were pelleted and the supernatant was discarded. Glycosylated proteins were removed by adding $0.5 \mathrm{~mL}$ of $1 \mathrm{X}$ elution buffer (binding buffer $+500 \mathrm{mM}$ D-glucose) and gently mixing for $1 \mathrm{hr}$ at ambient temperature. The beads were pelleted and the supernatant was saved as fraction F1B.

\subsection{Preparation of fractionated samples for LC/MS/MS analysis}

Albumin-depleted fractions for both Con A fractions (F1A \& F1B) were concentrated using vacuum centrifugation and resuspended to a final concentration of $1 \mathrm{mg} / \mathrm{mL}$ in $100 \mathrm{mM}$ ammonium bicarbonate, $\mathrm{pH}$ 8.0. Samples were applied to $10 \mathrm{kDa}$ MWCO Amicon Spin Filters (Millipore) and reduced, alkylated, and digested with trypsin as described [30].

\subsection{LC/MS/MS of proteins}

LC/MS/MS experiments of sera from 97 different study participants were performed using the Surveyor LC pump and autosampler connected in line with the ThermoFisher LCQ (San Jose, CA). For reproducibility, we did not do multiple shotgun sequence analyses of the same samples, but looked for replicates of each protein identified within each clinical group. Sera from 16 normal patients, 44 chronic HBV hepatitis patients, and $37 \mathrm{HBV}+$ patients with $\mathrm{HCC}$ were analyzed by LC/MS/MS. Samples were injected onto a peptide enrichment column $(\mathrm{C} 18)$ in the full loop mode. The eluent for the first 22 minutes of the gradient was diverted to waste to remove any salts in the sample. Flow to the column was established at 22 min onto a PicoFrit Biobasic $5 \mu \mathrm{m} \mathrm{C18}$ capillary column, (10 cm by 75 $\mu \mathrm{m}$ ID) (New Objective, Woburn, MA). The sample was then eluted using a gradient of $0.1 \%$ formic acid in water (J.T. Baker, solvent A) and $0.1 \%$ formic acid in acetonitrile (J.T. Baker, solvent B). The gradient was as follows: $0-22 \mathrm{~min}$, isocratic $100 \% \mathrm{~A} ; 22-50 \mathrm{~min}$, linear change to $60 \% \mathrm{~B} ; 50-100 \mathrm{~min}$, linear change to $80 \% \mathrm{~B} ; 100-125 \mathrm{~min}$, isocratic $80 \% \mathrm{~B} ; 125-135 \mathrm{~min}$, linear change to $100 \% \mathrm{~A} ; 135-150 \mathrm{~min}$, isocratic $100 \%$ A. The eluent from the capillary column was introduced into the LCQ source using nanospray ionization (capillary voltage at $2.2 \mathrm{~V}$ ). Gas phase fractionation was completed to survey the peptide masses from $\mathrm{m} / \mathrm{z}$ 350-750 and $m / z, 750-2000$. MS/MS was acquired in a data-dependent manner consisting of a single full MS followed by three successive MS/MS experiments. Data-dependent scanning was completed with an allowed repeat count of 5 over 90 seconds with dynamic exclusion for 25 different ions set at 180 seconds duration. 


\subsection{Database searching}

MS/MS data are analyzed using ThermoElectron's BioWorks 3.0 software using a human database of proteins (Swiss Prot database, release 7459). Protein identification was dependent upon Xcorr score fit. Protein matches are identified using two sets of criteria. First, strict Washburn criteria [32] (as distinct from probability-based criteria [33]) were used to identify proteins, based on the charge of the precursor peptide ion and the Xcorr assigned by Bioworks software. These criteria dictate that for ion trap data, the required Xcorr value for identification increases with increasing charge $(z=+3$, Xcorr $>3.5$; $z=+2$, Xcorr $>$ 2.2; and $z=+1$, Xcorr $>1.9$ ). These criteria allow for increased confidence in correct peptide sequence assignment within a single sample run.

Depending on the criteria we choose to match MS/MS spectra to peptides in the human database, the number of identified proteins changes. Decreasing the threshold for accepting a peptide match increases the number of likely false-positive matches. Since the ultimate aims of this project are to use identified peptides/proteins in a quantitative sense, we relaxed the criteria and allowed more protein identifications, based only on Xcorr score of $>1.2$ for all charge states. Our justification for this is two-fold. First, we anticipate the probability for the presence of a protein in serum is increased if it is repeatedly observed in our Sequest searches of multiple serum samples $(\geqslant 50 \%$ of samples per group). Second, we are able to pick out peptides that are more difficult to detect. These difficulties may be because the tryptic peptides for a given protein may be derived from low abundance molecules in the serum or because a peptide may give sub-optimal MS/MS spectra due to its chemical/physical properties. While we are aware that loosening our exclusion criteria will give greater uncertainty in our protein identifications, we feel it is necessary to do this to increase our overall yield of serum changes that may occur in the transition from hepatitis infection to HCC. Because we are taking liberties with our identification strategy, it is especially important to verify our identifications by using other independent methods that validate our protein matches (the stable isotope-based quantitative mass spectrometry detailed below).

\subsection{Analysis and statistics}

Samples and molecular data were encoded without personal identifiers. Data from BioWorks searches were exported as text files. Proteins were accepted as related to a disease state if a peptide corresponding to an identified protein was found in at least half of all peptide searches for samples in a participant's subgroup and were present in less than $50 \%$ of all other subgroups. Protein lists were then compared amongst subgroups to assign differences. Derived data was kept in Excel spreadsheets, where initial sorting and comparisons were done, with extensive use of Excel's Pivot Table function. Statistics were then analyzed using Prism software, starting with basic descriptive statistics to review the data content for each measure.

\subsection{Phenylisocyanate (PIC) labeling of peptide digests for quantitative analysis}

The paired sera samples from 10 chronic HBV hepatitis patients who progressed to HCC, along with sera from all other comparative groups (11 controls, 11 carriers for $\mathrm{HBV}, 6$ carriers with $\mathrm{HCV}$, and 17 patients with automimmune hepatitis) were randomly selected for measurement of AFPebp. PIC labeling of peptides used for quantitative analysis was carried out as described by Mason et al. [30]. AFPebp peptide (ISFPGSSESPLSSKR), a unique sequence from AFPebp, was purchased from New England Peptide (Gardner, MA) and diluted in water for labeling. PIC- $\mathrm{d}_{0}$ and PIC$\mathrm{d}_{5}$ were purchased from Sigma-Aldrich, and a standard curve of AFPebp- PIC- $\mathrm{d}_{5}$ was made for quantitative purposes. $1.5 \mathrm{ng}$ of pure PIC- $\mathrm{d}_{5}$ labeled peptide was then added as an internal standard post digestion to a mixture of PIC- $\mathrm{d}_{0}$ labeled tryptic peptides from a digest of whole serum. The peptides were then analyzed by LC/MS/MS using the same gradient described above, with the mass spectrometer set to probe masses from 500-900 amu, allowing one data-dependent scan per full scan. The ratio of the PIC- $\mathrm{d}_{5}$ peak area with the PIC- $\mathrm{d}_{0}$ area was then used to calculate the amount of the peptide in the sample. Amounts of AFPebp were calculated and $p$ values for differences in patient groups were determined using Prism software (GraphPad Software Inc., San Diego, CA). The standard deviation for AFPebp quantification in this method was $<20 \%$.

\section{Results}

\subsection{Fractionation of sera}

Albumin depletion was generally $85-90 \%$ for one injection and yielded approximately $3-5 \mathrm{mg}$ of protein from $0.1 \mathrm{~mL}$ of serum in the flow through fraction $(\mathrm{F} 1)$. 
Table 2

Unique proteins identified in chronic HBV hepatitis and HCC samples

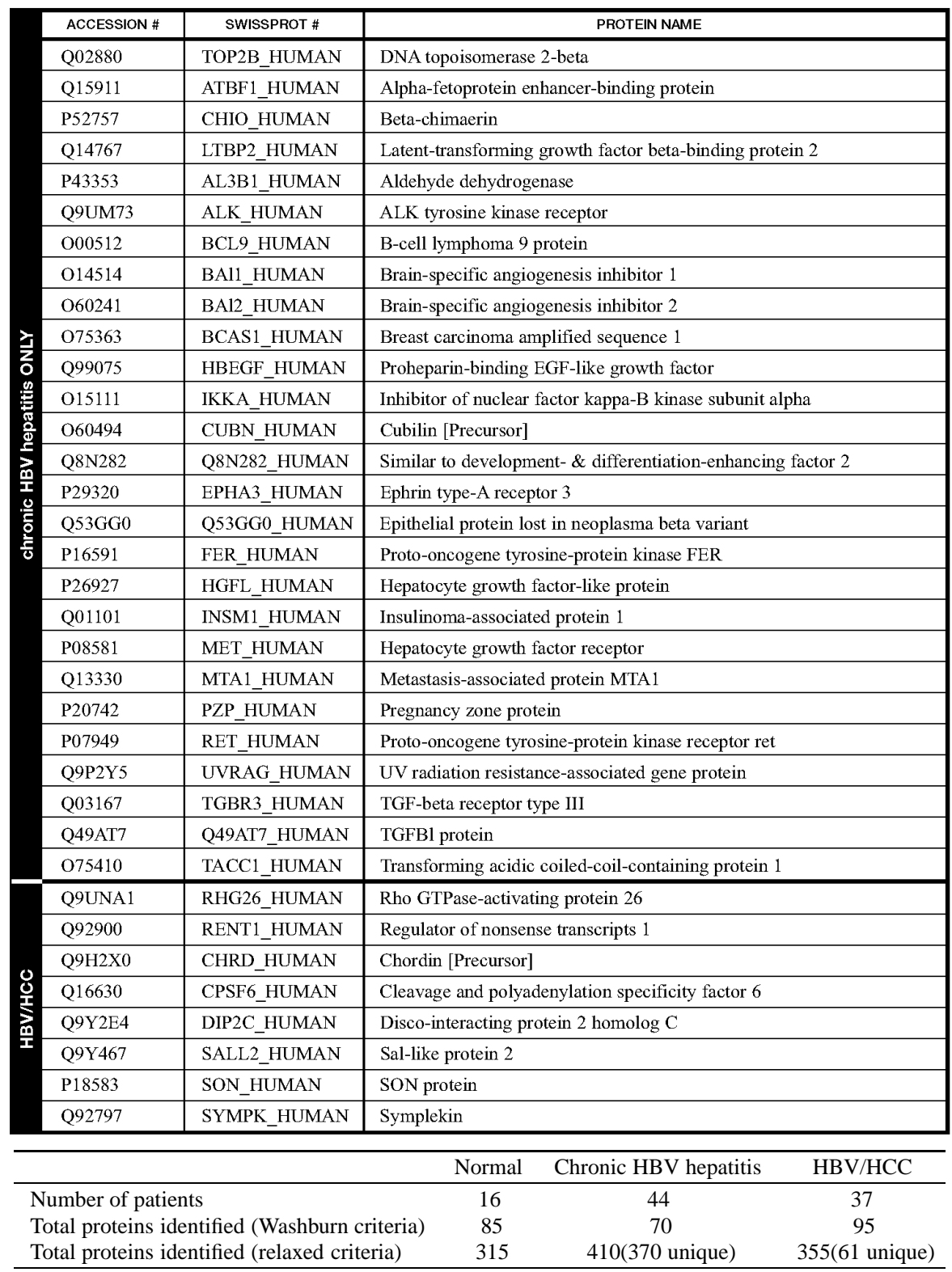

Repeat injection of F1 did not yield further albumin depletion. Recovery of glycoproteins from the batch purification method was generally $>70 \%$. It resulted in a fraction combined of non-glycosylated proteins with glycoproteins that do not bind Con A (F1A), and a Con A-bound glycoprotein fraction (F1B). Yields were generally higher in F1A $(\sim 2.5 \mathrm{mg}$ total protein per $100 \mu \mathrm{L}$ serum prep) as compared to yields for F1B ( $\sim 1.5 \mathrm{mg}$ total protein per $100 \mu \mathrm{L}$ serum prep).

\subsection{Identification of proteins in serum}

Our key findings from LC/MS/MS of combined F1A and F1B proteins are detailed in Table 2, an abbreviated table of protein identifications relevant to our work, based on proteins identified in 16 control samples, 44 chronic HBV hepatitis without cancer, and 37 chronic HBV hepatitis with HCC. For a peptide match from our Bioworks database to be considered as an identified protein, a given protein must be identified by at least 


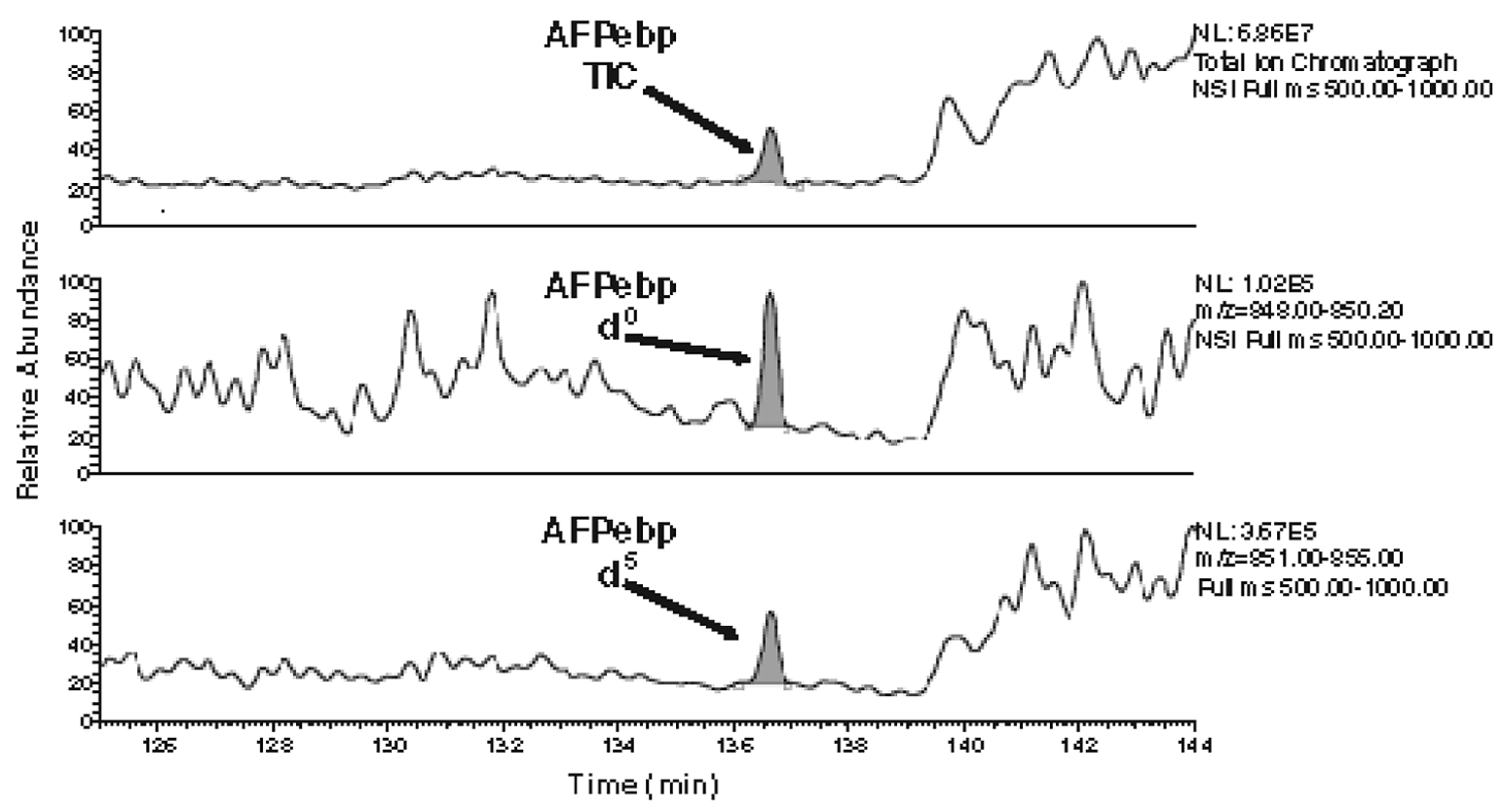

Fig. 1. Total ion chromatograph (TIC) of AFPebp in serum. Serum was spiked with d5-PIC labeled AFPebp peptide, digested with trypsin and subjected to LC/MS/MS. TIC was obtained and the area under the curve highlighted for the $\mathrm{d}^{0}$ (endogenous) and $\mathrm{d}^{5}$ (spiked) isotopes of AFPebp at $M^{2+} 849$ (B) and 852 (C) amu, respectively. This chromatograph is representative of the 64/65 of our experiments detecting AFPebp.

one peptide in $\geqslant 50 \%$ of all samples run per group and give an Xcorr score of $>1.2$. By loosening our criteria, the number of identified proteins increases approximately 4-5 fold. For the identifications under relaxed criteria, a larger number of proteins are observed for the two disease states than in controls. Since the higher abundance proteins are the same between groups, we think the greater number of lower abundance proteins in HBV states is most likely due to disease activity rather than the smaller number of control samples assayed. From these data, proteins of interest have been listed that are unique to a given patient subgroup and warrant further investigation (Table 2).

\subsection{Quantitative analysis of alpha-fetoprotein enhancer binding protein (AFPebp) peptide by LC/MS/MS}

Table 2 proteins are identified in serum from patients with the chronic HBV hepatitis state but not in control samples, are enriched in either the pre-cancer or HCC state (i.e., they disappear or appear as HCC develops), and are known to be involved in regulation of DNA repair, growth, or embryonic activities. These are thus candidate biomarkers for which there are some pathophysiological interpretations relevant to the transition from chronic HBV hepatitis to HCC. While these pro- teins are all identified repeatedly in $\geqslant 50 \%$ of serum samples for either disease state, all of these functionally interesting proteins have low Xcorr values between 1.2 and 1.8. Therefore, we would not consider the assignments to be correct without further study.

To test whether any of the biomarker candidates are correctly identified in these serum samples, we selected AFPebp to be further evaluated. Since AFP is the standard biomarker for HCC, its regulatory transcription factor (AFPebp) [34] might be relevant pathophysiologically. Very little previous work has been completed on AFPebp and it's role in HCC, with reports detailing its role in the regulation of AFP expression in hepatoma [35], and other cancers [36-40].

Protein digests of whole serum were labeled using phenylisocyanate $\left(P I C-d_{0}\right)$, spiked with PIC- $d_{5}$ standard, and analyzed using LC/MS/MS as described in "Methods." Any AFPebp that was identified was quantified, based on the spiked PIC-d $\mathrm{d}_{5}$ label. Sera from controls, and patients with HBV (carrier and chronic hepatitis states), autoimmune hepatitis, HCV carrier or $\mathrm{HBV} / \mathrm{HCC}$ were tested to evaluate their levels of AFPebp. Figure 1 shows the selective identification in serum of the two PIC labeled peptides $\left(d_{0} \& d_{5}\right)$ for AFPebp. The total ion chromatograph looks barren as most peptides are +3 and $>500$ amu.

Using the $d_{0} / d_{5}$ peptide labeling strategy, we obtained comparative data from serum samples. Figure 2 


\section{AFPebp peptide levels detected in the serum of cHBVh samples before and after HCC}

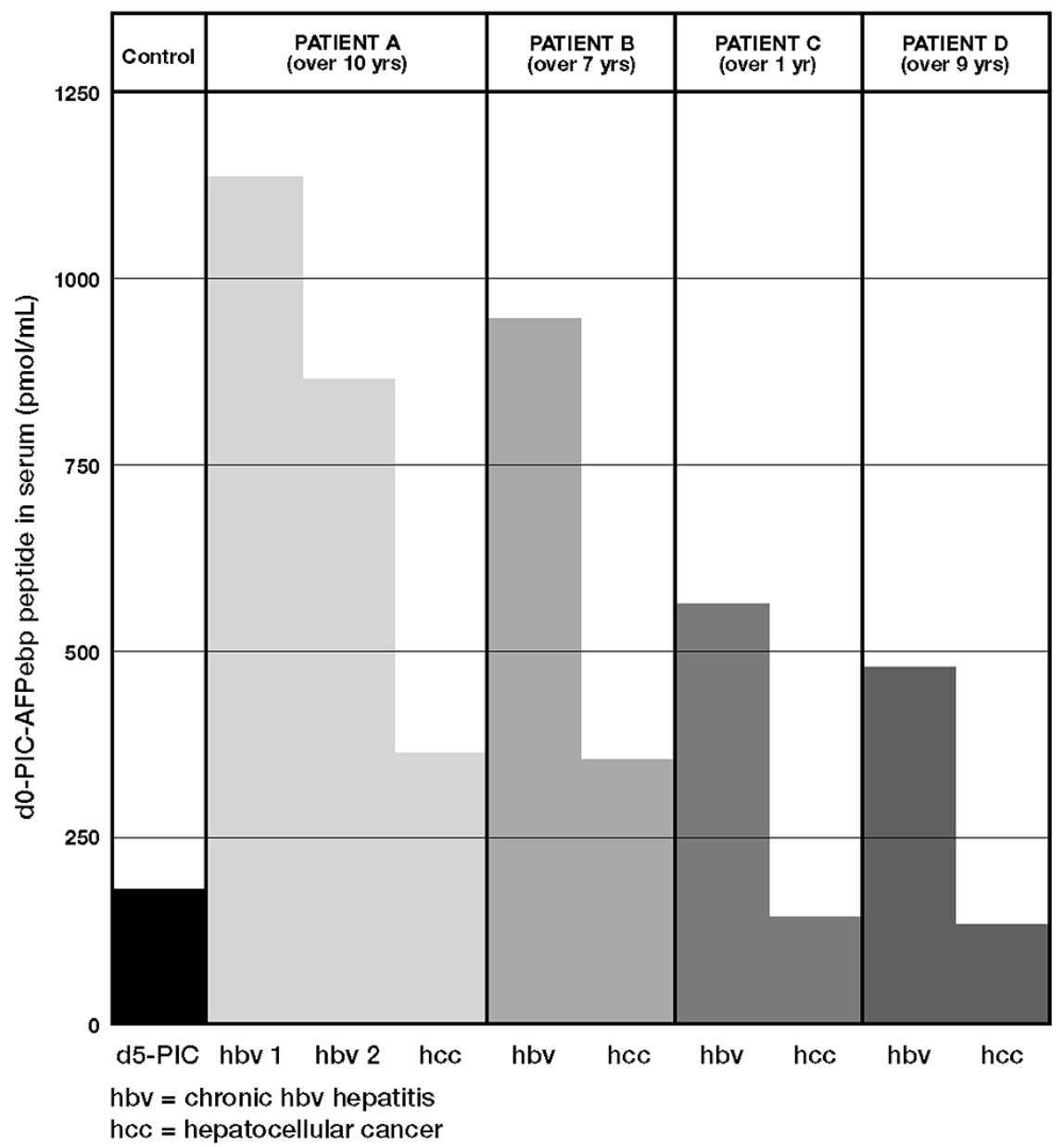

Fig. 2. Serum AFPebp levels in chronic HBV hepatitis patients. AFPebp levels were measured in serum samples before and after HCC was detected over short (1 year) to long duration (10 years). Amounts of AFPebp (pmol / $\mathrm{mL}$ ) were calculated as described in materials and methods.

shows levels of AFPebp peptide determined from four representative historical samples from chronic $\mathrm{HBV}$ hepatitis patients before and after they developed HCC. We observe the levels of AFPebp peptide derived from serum are greatest in samples during the pre-cancer stage, and they decrease when serum is taken when the patient has progressed to HCC regardless of the time between the serum sampling (1-10 yrs). The AFPebp levels decreased in all 10 of the paired cases $(p<$ 0.005) (Fig. 3). The levels of AFPebp detected in the paired samples in the chronic HBV hepatitis state was variable, which may explain the differences observed in the overall decrease in AFPebp levels during HCC.

AFP levels in our 10 paired samples did not change as consistently as the AFPebp levels (data not shown).
In six of the pairs, the AFP levels rose with HCC development, but in two cases there was no rise, in one case the levels fell with HCC, and in one case, the AFP levels were already high with chronic HBV hepatitis and did not change with HCC.

Levels of AFPebp found in the sera from different participant classes were compared and subgroup differences $(p<0.0001)$ were determined by ANOVA. Figure 4 shows the distribution and mean levels of AFPebp in the different groups. Notice that normal controls and HBV and HCV carriers had low levels of AFPebp. AFPebp levels in chronic HBV hepatitis were the highest. HBV/HCC patients had higher levels than those for normal controls and $\mathrm{HBV}$ and $\mathrm{HCV}$ carriers, but lower levels than those observed for chronic HBV hep- 


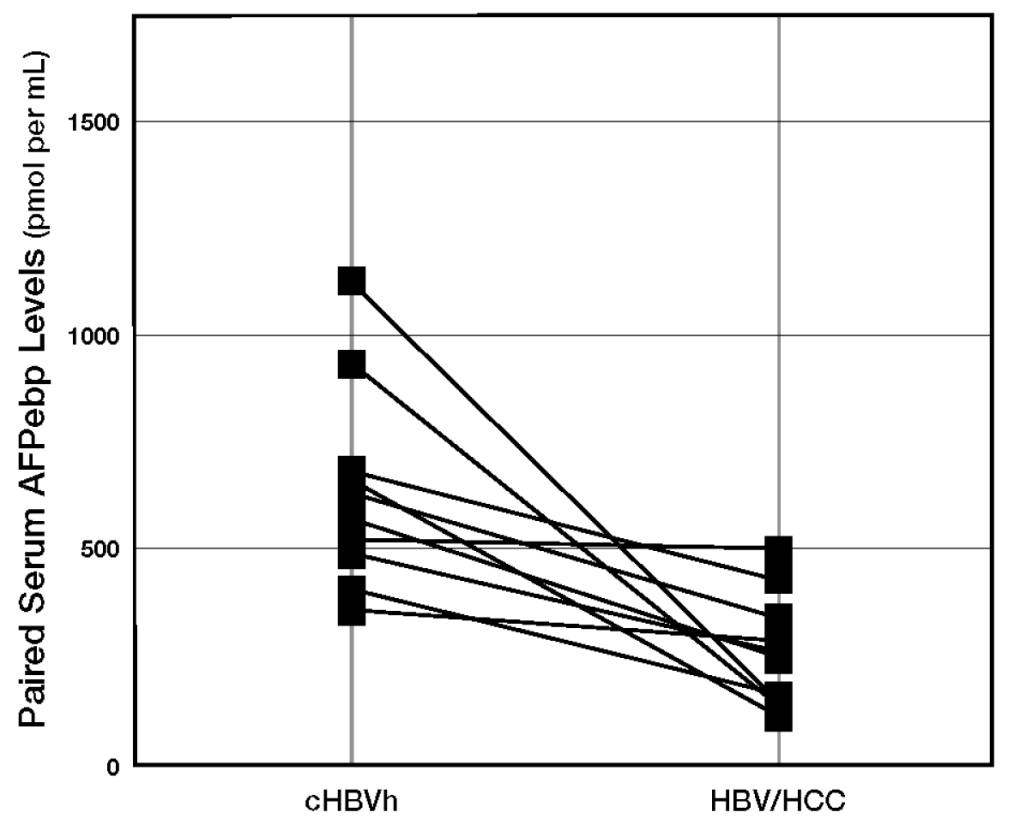

Fig. 3. AFPebp serum levels in 10 paired samples from patients transitioning from chronic HBV hepatitis (cHBVh) to HCC. Amounts of AFPebp $(\mathrm{pmol} / \mathrm{mL}$ ) were calculated as described in materials and methods. AFPebp levels consistently dropped in this transition to HCC $(p<0.005)$.

atitis. Levels of AFPebp in patients with autoimmune hepatitis were similar to those in HBV/HCC.

\section{Discussion and conclusions}

HCC is the major type of liver cancer, yet there is no reliable diagnostic or prognostic test. Genetic screening is predicted to reveal at risk individuals, but genes for HCC are not fully characterized [41]. In addition to genetic screening, expression of proteins in serum [29], including epigenetic markers [42], may indicate the development or the extent of cancer development.

To identify candidates for protein cancer biomarkers, recent advances in mass spectrometry have made it possible to detect thousands of proteins in serum [43], but there are seemingly endless protocol variations. Different sample preparations, such as depletion of abundant proteins, can focus the search on selected proteins, and different protease digestion protocols have been employed to improve peptide coverage. The different identification algorithms employed yield varied results, as do replicated runs of the same sample. There is limitation in the dynamic range, sensitivity, and capability of different instruments, with the result that there is no single, best approach. There are three sequences in the initial discovery of a protein marker: identification, verification of its presence, and determination of the sensitivity, specificity, and predictive value. Our study addresses only the first two requirements, and further studies are needed to assess the sensitivity, specificity, and predictive value for AFPebp and HCC.

An additional method we used to increase the sensitivity to identify low abundance proteins from those identified with the more rigorous Washburn criteria [32] was to relax the Sequest criteria. Only when we relaxed the Sequest criteria did we identify proteins whose known functions were of potential interest for roles in the development of HCC (Table 2). Since we relaxed the typically used high confidence criteria for assignments, our final protein identifications may be spurious. Hence the critical need to confirm and quantify their presence, for which an alternative, reproducible method is required. A time-honored method to quantify peptides has been some form of immunoassay but, as yet, there is no available AFPebp-specific antibody. Stable isotope labeling offers a strategy both to validate as well as quantify peptides from shotgun sequencing studies. Using this approach, we confirm that a peptide that is specific to one of the low abundance proteins in Table 2, AFPebp, is present in serum (Fig. 1). Indeed, AFPebp was measured in whole serum from all but one of the 65 samples assayed, a much higher sensitivity than from the shotgun sequencing when only 50 95\% of samples in chronic HBV hepatitis samples and $<50 \%$ of the other samples had any AFPebp peptide 


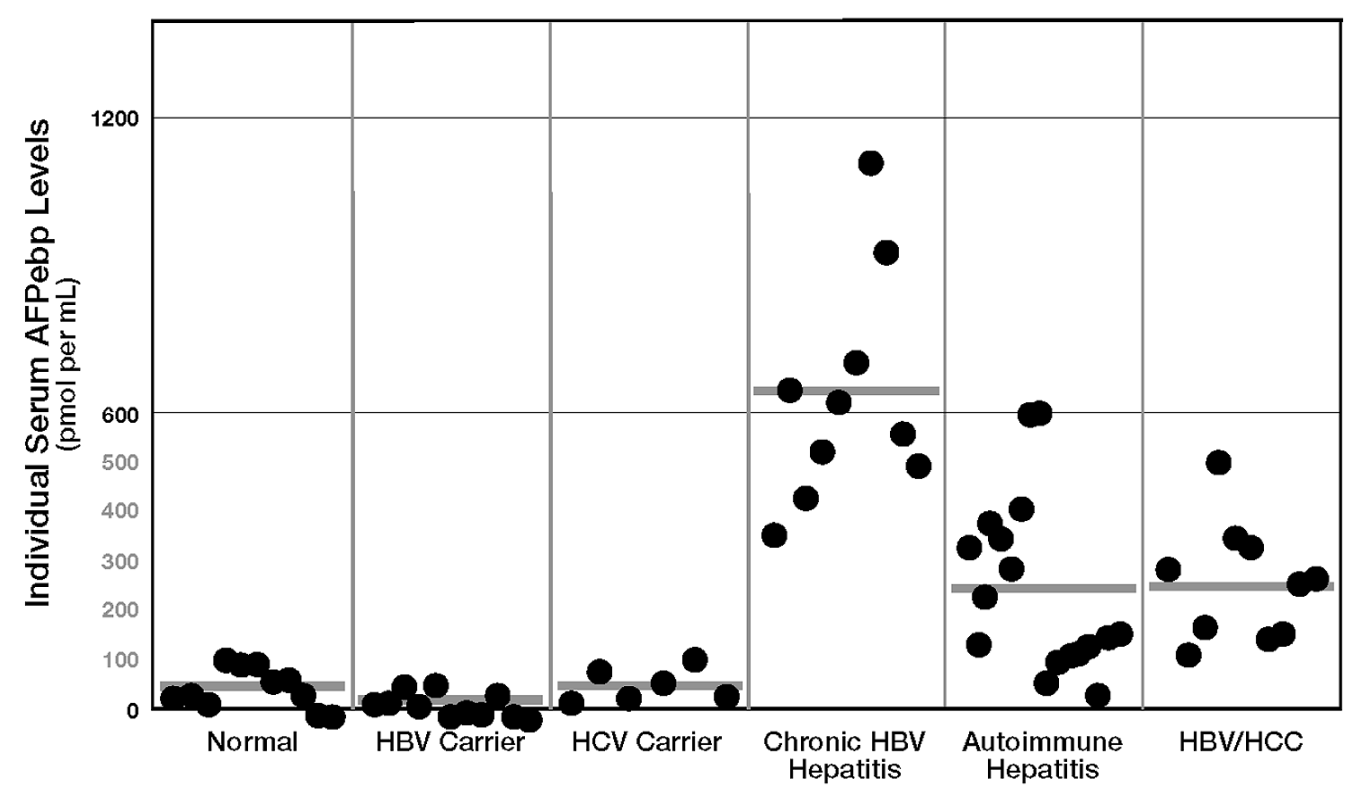

Fig. 4. Sixty-five AFPebp serum levels in controls and different disease subgroups. Serum AFPebp levels (pmol/mL) were measured in healthy controls and 5 different disease groups. The bar represents the mean for all samples included in the study. The changes were determined to be significant by ANOVA $(p<0.0001)$.

identified. This is an important verification, since its Xcorr value from shotgun sequencing was always well below the normal cutoff ( 2.2 for $\left.M^{2+}\right)$ in all samples tested (data not shown).

AFPebp is not glycosylated and, consequently, was present in both Con A bound and unbound fractions. Though our glycoprotein fractionation was not necessarily relevant for its enrichment, this does not invalidate the strategy for other proteins that will only be determined in further experiments. We have only verified the presence of AFPebp, but we propose that the other proteins in Table 2 merit experiments to evaluate them.

Our quantitative data identify that AFPebp is present in low abundance in normal blood sera; the levels increase during chronic HBV hepatitis, and then decrease as HCC develops. For an initial exploration of the specificity of AFPebp, we measured levels in controls, patients with carrier hepatitis $\mathrm{B}$ or $\mathrm{C}$ status, chronic autoimmune hepatitis, chronic HBV hepatitis, and HCC associated with HBV (Fig. 4). The prevalence of AFPebp in the sera from controls is low and equivalent to viral carriers (HBV or HCV). Patients with autoimmune hepatitis have levels similar to patients with HBV/HCC, but lower than the levels observed in the chronic HBV hepatitis state. Further studies of more patients in these categories will allow correlation testing of AFPebp, including tumor size, cirrhosis,/noncirrhosis, viral loads, and treatments. These variables along with examination of patients with other liver diseases such as chronic HCV hepatitis or non-viral cirrhosis, will be necessary before the clinical specificity and predictive value of AFPebp can be determined. Additional technical studies would also be informative, including the use of different AFPebp peptide sequences for stable isotope-labeling studies.

AFP levels did not change as consistently as did AFPebp levels when the 10 patients with chronic HBV hepatitis transitioned to HCC. This inconsistency with AFP is well known as referenced in the introduction. Only further studies will clarify if AFPebp measurement has potential as a clinically useful marker of this transition.

Our data provides evidence that AFPebp is present in serum, increases in chronic HBV hepatitis, and reduces as HCC develops. Since AFPebp is a tumor suppressor [38], our data is consistent with its pathophysiological role to protect against the formation of HCC in patients with chronic HBV hepatitis. We also propose that decreasing AFPebp levels in chronic HBV hepatitis patients predisposes to HCC. We do not know the mechanism for this initial AFPebp upregulation, followed by its relative downregulation, but its role may be protective and its reduction could predispose to cancer. Thus, the AFPebp changes we have identified may represent an important regulatory mechanism in the pathophysiology of HCC that merits further study 


\section{Acknowledgments}

The authors thank the organizing committee, sponsors and participants in the Second Lieutenant Andrew J. Torres (USMC), Memorial Golf Tournament and HMRI for their financial support.

\section{References}

[1] P.A. Farazi and R.A. DePinho, Hepatocellular carcinoma pathogenesis: from genes to environment, Nature Reviews 6(9) (2006), 674-687.

[2] N.L. Lazarevich, Molecular mechanisms of alpha-fetoprotein gene expression, Biochemistry 65(1) (2000), 117-133.

[3] T.M. Block, J. Marrero, R.G. Gish, M. Sherman, W.T. London, S. Srivastava and P.D. Wagner, The degree of readiness of selected biomarkers for the early detection of hepatocellular carcinoma: notes from a recent workshop, Cancer Biomark 4(1) (2008), 19-33.

[4] K. Han, G.N. Tzimas, J.S. Barkun, P. Metrakos, J.L. Tchervenkov, N. Hilzenrat, P. Wong and M. Deschenes, Preoperative alpha-fetoprotein slope is predictive of hepatocellular carcinoma recurrence after liver transplantation, Canadian Journal of Gastroenterology = Journal Canadien de Gastroenterologie 21(1) (2007), 39-45.

[5] T.I. Huo, C.Y. Hsia, C.J. Chu, Y.H. Huang, W.Y. Lui, J.C. Wu, P.C. Lee, C.W. Chi and S.D. Lee, The predictive ability of serum alpha-fetoprotein for hepatocellular carcinoma is linked with the characteristics of the target population at surveillance, Journal of Surgical Oncology 95(8) (2007), 645-651.

[6] C.M. Lo, Editorial on "a revised scoring system utilizing serum alphafetoprotein levels to expand candidates for living donor liver transplantation in hepatocellular carcinoma", Surgery 142(1) (2007), 119-120.

[7] C.D. Mann, C.P. Neal, G. Garcea, M.M. Manson, A.R. Dennison and D.P. Berry, Prognostic molecular markers in hepatocellular carcinoma: a systematic review, Eur J Cancer 43(6) (2007), 979-992.

[8] J.A. Marrero, Z. Feng, Y. Wang, M.H. Nguyen, A.S. Befeler, L.R. Roberts, K.R. Reddy, D. Harnois, J.M. Llovet, D. Normolle et al., Alpha-fetoprotein, des-gamma carboxyprothrombin, and lectin-bound alpha-fetoprotein in early hepatocellular carcinoma, Gastroenterology 137(1) (2009), 110-118.

[9] S. Sun, N.P. Lee, R.T. Poon, S.T. Fan, Q.Y. He, G.K. Lau and J.M. Luk, Oncoproteomics of hepatocellular carcinoma: from cancer markers' discovery to functional pathways, Liver Int 27(8) (2007), 1021-1038.

[10] W. Sun, B. Xing, Y. Sun, X. Du, M. Lu, C. Hao, Z. Lu, W. Mi, S. Wu, H. Wei et al., Proteome analysis of hepatocellular carcinoma by two-dimensional difference gel electrophoresis: novel protein markers in hepatocellular carcinoma tissues, $\mathrm{Mol}$ Cell Proteomics 6(10) (2007), 1798-1808.

[11] M.L. Volk, J.C. Hernandez, G.L. Su, A.S. Lok and J.A. Marrero, Risk factors for hepatocellular carcinoma may impair the performance of biomarkers: a comparison of AFP, DCP, and AFP-L3. Cancer Biomark 3(2) (2007), 79-87.

[12] H.T. Cheng, Y.H. Chang, Y.Y. Chen, T.H. Lee, D.I. Tai and D.Y. Lin, AFP-L3 in chronic liver diseases with persistent elevation of alpha-fetoprotein, J Chin Med Assoc 70(8) (2007), $310-317$.
[13] M.A. Comunale, M. Wang, J. Hafner, J. Krakover, L. Rodemich, B. Kopenhaver, R.E. Long, O. Junaidi, A.M. Bisceglie, T.M. Block et al., Identification and development of fucosylated glycoproteins as biomarkers of primary hepatocellular carcinoma, Journal of Proteome Research 8(2) (2009), 595-602.

[14] A. Mehta and T.M. Block, Fucosylated glycoproteins as markers of liver disease, Disease Markers 25(4-5) (2008), 259265.

[15] M.A. Comunale, M. Lowman, R.E. Long, J. Krakover, R. Philip, S. Seeholzer, A.A. Evans, H.W. Hann, T.M. Block and A.S. Mehta, Proteomic analysis of serum associated fucosylated glycoproteins in the development of primary hepatocellular carcinoma, Journal of Proteome Research 5(2) (2006), 308-315.

[16] R. Goldman, H.W. Ressom, M. Abdel-Hamid, L. Goldman, A. Wang, R.S. Varghese, Y. An, C.A. Loffredo, S.K. Drake, S.A. Eissa et al., Candidate markers for the detection of hepatocellular carcinoma in low-molecular weight fraction of serum, Carcinogenesis 28(10) (2007), 2149-2153.

[17] Q.Y. He, R. Zhu, T. Lei, M.Y. Ng, J.M. Luk, P. Sham, G.K. Lau and J.F. Chiu, Toward the proteomic identification of biomarkers for the prediction of HBV related hepatocellular carcinoma, Journal of Cellular Biochemistry 103(3) (2008), 740-752.

[18] S. Kanmura, H. Uto, K. Kusumoto, Y. Ishida, S. Hasuike, K. Nagata, K. Hayashi, A. Ido, S.O. Stuver and H. Tsubouchi, Early diagnostic potential for hepatocellular carcinoma using the SELDI ProteinChip system, Hepatology Baltimore, Md 45(4) (2007), 948-956.

[19] I.N. Lee, C.H. Chen, J.C. Sheu, H.S. Lee, G.T. Huang, D.S. Chen, C.Y. Yu, C.L. Wen, F.J. Lu and L.P. Chow, Identification of complement $\mathrm{C} 3 \mathrm{a}$ as a candidate biomarker in human chronic hepatitis $\mathrm{C}$ and HCV-related hepatocellular carcinoma using a proteomics approach, Proteomics 6(9) (2006), 2865-2873.

[20] I.N. Lee, C.H. Chen, J.C. Sheu, H.S. Lee, G.T. Huang, C.Y. Yu, F.J. Lu and L.P. Chow, Identification of human hepatocellular carcinoma-related biomarkers by two-dimensional difference gel electrophoresis and mass spectrometry, Journal of Proteome Research 4(6) (2005), 2062-2069.

[21] X.E. Liu, L. Desmyter, C.F. Gao, W. Laroy, S. Dewaele, V. Vanhooren, L. Wang, H. Zhuang, N. Callewaert, C. Libert et al., N-glycomic changes in hepatocellular carcinoma patients with liver cirrhosis induced by hepatitis B virus, Hepatology Baltimore, Md 46(5) (2007), 1426-1435.

[22] D. Zhang, S.G. Lim and E.S. Koay, Proteomic identification of down-regulation of oncoprotein DJ-1 and proteasome activator subunit 1 in hepatitis B virus-infected well-differentiated hepatocellular carcinoma, International Journal of Oncology 31(3) (2007), 577-584.

[23] P. Shalhoub, S. Kern, S. Girard and L. Beretta, Proteomicbased approach for the identification of tumor markers associated with hepatocellular carcinoma, Disease Markers 17(4) (2001), 217-223.

[24] E. Orvisky, S.K. Drake, B.M. Martin, M. Abdel-Hamid, H.W. Ressom, R.S. Varghese, Y. An, D. Saha, G.L. Hortin, C.A. Loffredo et al., Enrichment of low molecular weight fraction of serum for MS analysis of peptides associated with hepatocellular carcinoma, Proteomics 6(9) (2006), 2895-2902.

[25] A.D. Riggs and Z. Xiong, Methylation and epigenetic fidelity, Proceedings of the National Academy of Sciences of the United States of America 101(1) (2004), 4-5.

[26] J. Wang, Y. Qin, B. Li, Z. Sun and B. Yang, Detection of aberrant promoter methylation of GSTP1 in the tumor and 
serum of Chinese human primary hepatocellular carcinoma patients, Clinical Biochemistry 39(4) (2006), 344-348.

[27] M.A. Battle, G. Konopka, F. Parviz, A.L. Gaggl, C. Yang, F.M. Sladek and S.A. Duncan, Hepatocyte nuclear factor 4alpha orchestrates expression of cell adhesion proteins during the epithelial transformation of the developing liver, Proceedings of the National Academy of Sciences of the United States of America 103(22) (2006), 8419-8424.

[28] J.D. Groopman, D. Johnson and T.W. Kensler, Aflatoxin and hepatitis B virus biomarkers: a paradigm for complex environmental exposures and cancer risk, Cancer Biomark 1(1) (2005), 5-14.

[29] L.M. Wright, J.T. Kreikemeier and C.J. Fimmel, A concise review of serum markers for hepatocellular cancer, Cancer Detection and Prevention 31(1) (2007), 35-44.

[30] D.E. Mason and D.C. Liebler, Quantitative analysis of modified proteins by LC-MS/MS of peptides labeled with phenyl isocyanate, Journal of Proteome Research 2(3) (2003), 265272.

[31] E.Y. Song, S.K. Kang, Y.C. Lee, Y.G. Park, T.H. Chung, D.H. Kwon, S.M. Byun and C.H. Kim, Expression of bisecting Nacetylglucosaminyltransferase-III in human hepatocarcinoma tissues, fetal liver tissues, and hepatoma cell lines of Hep3B and HepG2, Cancer Investigation 19(8) (2001), 799-807.

[32] M.P. Washburn, D. Wolters and J.R. Yates, 3rd, Large-scale analysis of the yeast proteome by multidimensional protein identification technology, Nature Biotechnology 19(3) (2001), 242-247.

[33] W.J. Qian, T. Liu, M.E. Monroe, E.F. Strittmatter, J.M. Jacobs, L.J. Kangas, K. Petritis, D.G. Camp, 2nd and R.D. Smith, Probability-based evaluation of peptide and protein identifications from tandem mass spectrometry and SEQUEST analysis: the human proteome, Journal of Proteome Research 4(1) (2005), 53-62.

[34] H. Yasuda, A. Mizuno, T. Tamaoki and T. Morinaga, ATBF1, a multiple-homeodomain zinc finger protein, selectively downregulates AT-rich elements of the human alpha-fetoprotein gene, Molecular and Cellular Biology 14(2) (1994), 13951401 .

[35] T. Ninomiya, K. Mihara, K. Fushimi, Y. Hayashi, T.
Hashimoto-Tamaoki and T. Tamaoki, Regulation of the alphafetoprotein gene by the isoforms of ATBF1 transcription factor in human hepatoma, Hepatology Baltimore, Md 35(1) (2002), 82-87.

[36] M. Iida, J. Imura, T. Furuichi, T. Sawada, H. Nagawa and T. Fujimori, Alteration of the AT motif binding factor- 1 expression in alpha-fetoprotein producing gastric cancer: is it an event for differentiation and proliferation of the tumors? Oncology Reports 11(1) (2004), 3-7.

[37] Z. Zhang, H. Yamashita, T. Toyama, H. Sugiura, Y. Ando, K. Mita, M. Hamaguchi, M. Kawaguchi, Y. Miura and H. Iwase, ATBF1-a messenger RNA expression is correlated with better prognosis in breast cancer, Clin Cancer Res 11(1) (2005), 193-198.

[38] X. Sun, H.F. Frierson, C. Chen, C. Li, Q. Ran, K.B. Otto, B.L. Cantarel, R.L. Vessella, A.C. Gao, J. Petros et al., Frequent somatic mutations of the transcription factor ATBF1 in human prostate cancer, Nature Genetics 37(4) (2005), 407-412.

[39] Y. Mori, H. Kataoka, Y. Miura, M. Kawaguchi, E. Kubota, N. Ogasawara, T. Oshima, S. Tanida, M. Sasaki, H. Ohara et al., Subcellular localization of ATBF1 regulates MUC5AC transcription in gastric cancer, International Journal of Cancer 121(2) (2007), 241-247.

[40] Y. Supriatna, T. Kishimoto, M. Furuya, N. Tochigi, H. Ishiguro, D. Tosh and H. Ishikura, Expression of liver-enriched nuclear factors and their isoforms in alpha-fetoprotein-producing gastric carcinoma cells, Experimental and Molecular Pathology 82(3) (2007), 316-321.

[41] E. Segal, C.B. Sirlin, C. Ooi, A.S. Adler, J. Gollub, X. Chen, B.K. Chan, G.R. Matcuk, C.T. Barry, H.Y. Chang et al., Decoding global gene expression programs in liver cancer by noninvasive imaging, Nature Biotechnology 25(6) (2007), 675-680.

[42] A.G. Rivenbark and W.B. Coleman, The use of epigenetic biomarkers for preclinical detection of hepatocellular carcinoma: potential for noninvasive screening of high-risk populations, Clin Cancer Res 13(8) (2007), 2309-2312.

[43] G.S. Omenn, R. Aebersold and Y.K. Paik, 7(th) HUPO World Congress of Proteomics: launching the second phase of the HUPOPlasma Proteome Project (PPP-2) 16-20 August 2008, Amsterdam, The Netherlands, Proteomics 9(1) (2009), 4-6. 


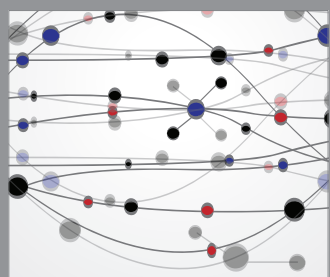

The Scientific World Journal
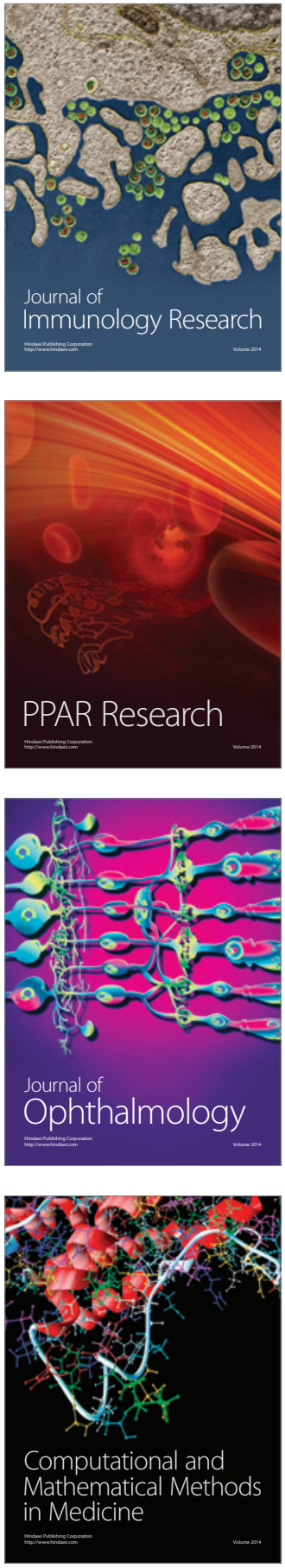

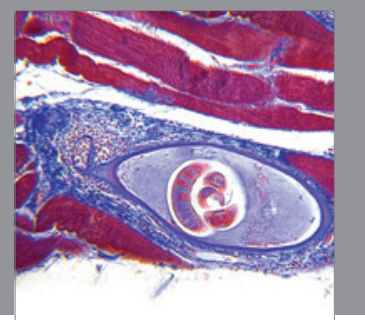

Gastroenterology

Research and Practice
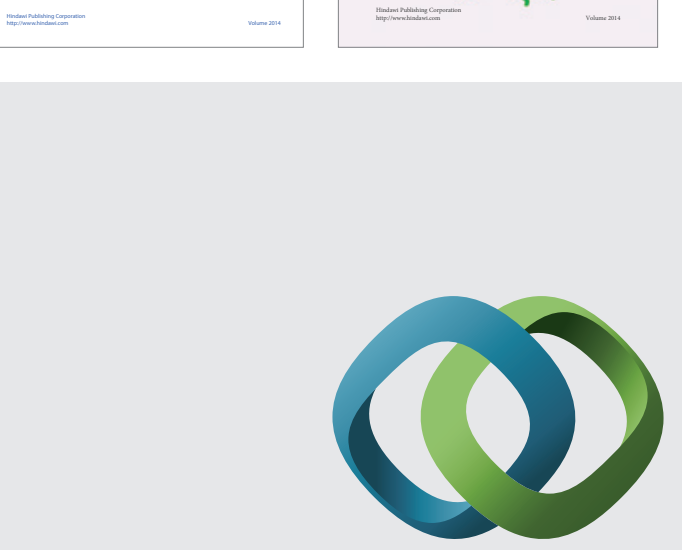

\section{Hindawi}

Submit your manuscripts at

http://www.hindawi.com
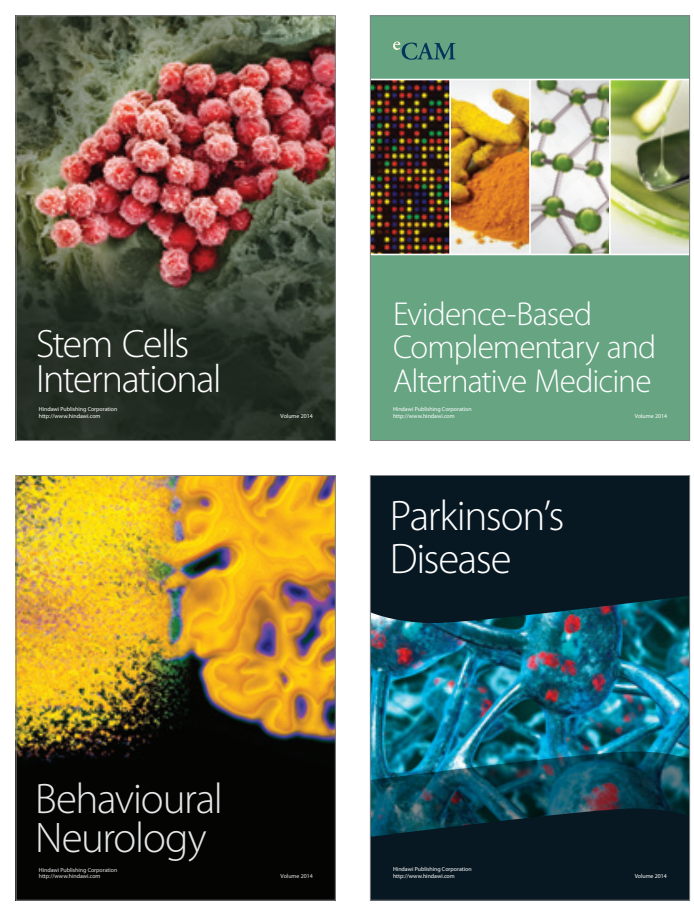

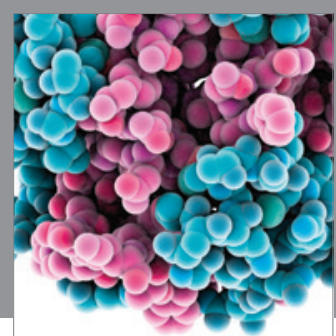

Journal of
Diabetes Research

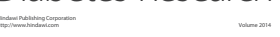

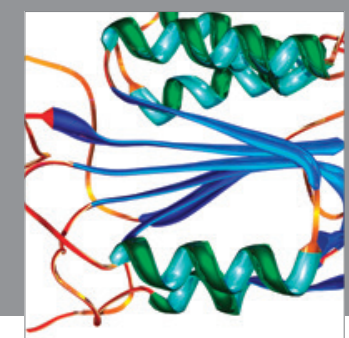

Disease Markers
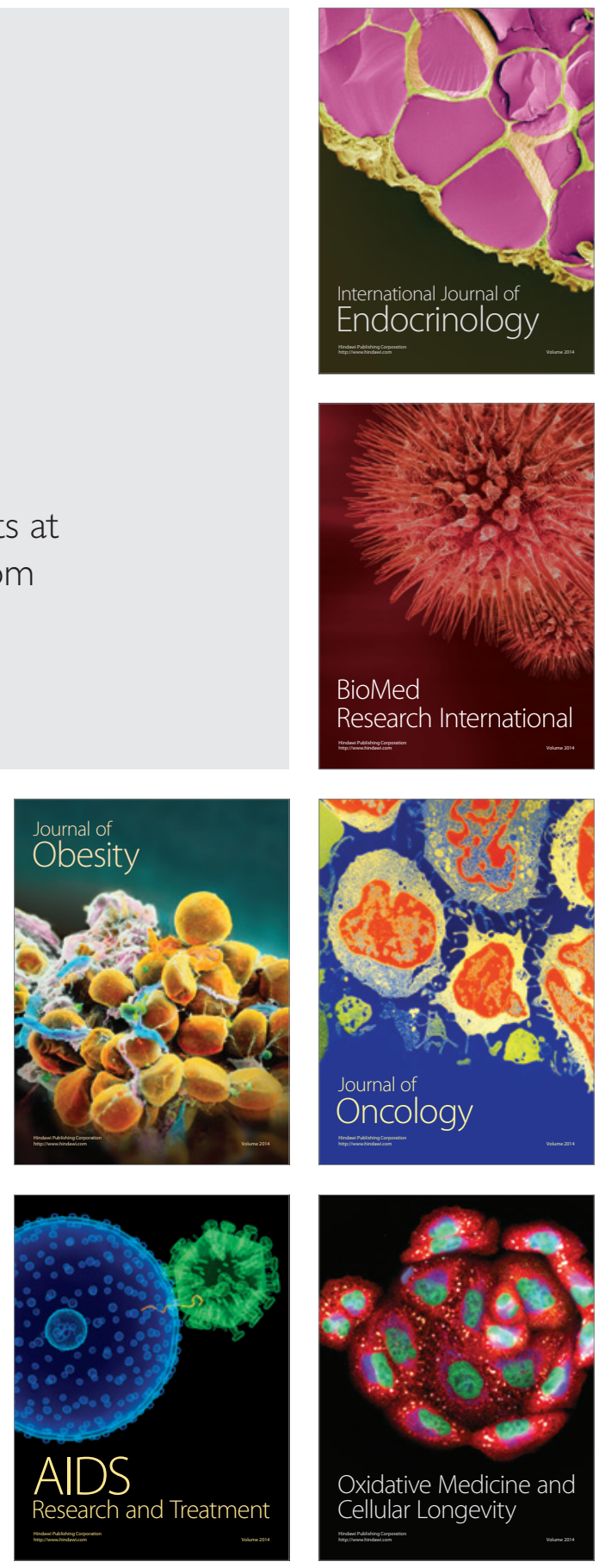